\section{"Consiguió su instinto dejándome enferma...". Alcances y prácticas de justicia frente al delito de violación en Concepción en el siglo $\mathrm{XIX}^{\star}$}

"She Got her instinct ... leaving me very ill." Scope and practices of justice against the crime of rape in nineteenth century Concepción

\section{Dra. Yéssica GonzÁlez-Gómez}

\section{Resumen}

Este artículo aborda el estudio de la violencia sexual ejercida sobre el cuerpo femenino, materializada en el delito de violación, en la

\footnotetext{
Este artículo tributa al proyecto DIUFRO N¹20503 "Matrimonio, conflicto y violencia en la Araucanía en los siglos XVII y XIX", financiado por la Dirección de Investigación de la Universidad de La Frontera en Temuco-Chile. La autora agradece el apoyo al desarrollo de esta pesquisa.

** Doctora en Historia Iberoamericana, académica e investigadora del Departamento de Ciencias Sociales de la Universidad de La Frontera, Temuco-Chile. Casilla 54-D. Correo electrónico yessica. gonzalez@ufrontera.cl.
}

provincia de Concepción, en el siglo XIX. A partir del estudio de expedientes criminales y en base al método de estudio de casos, interesa determinar la incidencia de esta forma de delitos y su impacto en las visiones y discursos dominantes dentro de la sociedad y a través del funcionamiento de las instituciones y las prácticas de justicia. El énfasis estará en demostrar el trato desigual del que fueron objeto las víctimas a partir de dichas prácticas dentro de un espacio y sociedad regional.

Palabras claves: Concepción, siglo XIX, violencia sexual, cuerpos, prácticas de justicia.

\begin{abstract}
This article deals with the study of sexual violence against the female body, embodied in the crime of rape in the province of Concepcion, in the nineteenth century. From the study of criminal records and based on the method of case studies, we are interested in determining the incidence of this form of crime and its impact on the visions and dominant discourses within society and through the functioning of institutions and practices Justice. The emphasis will be on demonstrating the unequal treatment of the victims within a regional space and society.
\end{abstract}

Keywords: Concepcion nineteenth century, traditional society, sexual violence, justice practices. 


\section{Catalina y su mal lograda historia....}

El lunes 19 de febrero de 1872, alrededor de la una de la tarde, en la localidad de Chepe, cercana a la ciudad de Concepción, al tiempo que María Juana Leal se hallaba en casa de su madre, José Cruz Soto entraba en su hogar para, en un acto brutal, ultrajar a Catalina Manríquez, su hija adoptiva de diez años. Ese mismo día, por la tarde, María encontraría en el piso de su rancho a la niña Catalina, desmayada y con evidentes signos del brutal ataque. Ante la dramática escena, y pese a la precariedad de sus medios, la mujer optó por hacer público el hecho, tomando a la pequeña para concurrir a las autoridades e interponer la denuncia respecto de lo que evidenciaba ser un acto atroz (Albornoz 2014: 50-52; Palma 2014: 14) ${ }^{1}$. Dicha actitud, junto con evidenciar cierto conocimiento respecto de los protocolos de justicia, advierten el uso activo de los mismos por parte de los sectores populares, con mayor o menor grado de éxito, dependiendo de los objetivos perseguidos (Albornoz 2014: 50-52; Bravo 2015:79-103)².

Para el periodo estudiado los procedimientos de justicia, seguían regulados por las disposiciones heredadas del régimen colonial (Real Recopilación de Leyes de Indias, Tomo II, Libro VII, Título $8^{\circ}$ y la Novísima Recopilación de 1805 (Tomo V, Libro XII, tit. 27, 29 y 32), textos que a su vez remiten a lo dispuesto en las Siete Partidas: Partida VII, Tít. 19 y 20, Ley 1 y 3), en lo que definimos como una fase transicional del derecho previa a la promulgación del Código Penal del año 1874, donde lo relativo al delito de violación se encuentra contenido en el Libro II, Título VII, Sección V, art. 361, 362; Sección VI, Art. 367; Sección VII, art. 386-374 y Sección VIII, art. 373-374, respectivamente. Para entonces, según Palma "La justicia debía cumplir una función mediadora y moderadora entre el Estado y las comunidades, procurando asentar el estado de derecho y el imperio de la ley".

Se usa en este artículo, la diferenciación efectuada por la autora entre los conceptos de "justicia judicial" y "cultura jurídica". La primera, remite a la actuación y los criterios empleados por los jueces como depositarios de la legitimidad amparada en el conocimiento de las leyes; la segunda, al conjunto de "saberes doctrinales y prácticos, relacionados tanto con el derecho y su aplicación en instancias de justicia, como con su difusión en escritos institucionales o privados".
En el desplazamiento desde el rancho a la ciudad, la víctima fue expuesta a la contemplación de conocidos y vecinos en un acto que buscó hacer públicas las secuelas de un ataque que no tuvo otros testigos que sus protagonistas al momento de su perpetración. El dramatismo de este cuadro fue aumentado por un peregrinaje en el que Catalina no dejó de padecer los efectos derivados de la traumática experiencia (Farge 2008: 25)3. La pieza documental aludida abunda en referencias a la "estropeada" condición de la víctima y sus continuas "lamentaciones", tal como ilustra la siguiente cita:

\begin{abstract}
El diecinueve de febrero dejé cuidando mi casa que tengo en Chepe a mi hija adoptiva Catalina Márquez que anda en los diez años de edad, mientras yo fui a ver a mi madre por el lugar (...). Cuando regresé encontré a la Catalina de espaldas sin poderse mover, le interrogué que tenía y me dijo que José Cruz Soto la había dejado en ese estado sin poderse mover. Tal era el dolor que sentía. Había allí una gran cantidad de sangre que había arrojado la niña, quien siempre continuó arrojando sangre por todo el camino desde Chepe al Hospital. Yo presencié también el reconocimiento que hizo el médico (...) y vi que la niña Catalina estaba enteramente violada" (ANS, FJC, Leg. 193, exp. 28, fjs.1-25.).
\end{abstract}

\section{Introducción}

La pieza aludida forma parte de un corpus de 121 expedientes correspondientes a denuncias por delitos de connotación sexual consignadas en Concepción, de los cuales se han seleccionado algunas unidades documentales a modo de representación de los rasgos de esta forma de delitos y sus alcances. Se trata de unidades de conservación contenidas dentro del Fondo Judiciales de Concepción del Archivo Nacional

Para A. Farge las expresiones de sufrimiento, las emociones y los sentimientos importan en la historia como objeto de análisis, al igual que la forma en que las sociedades lo captaron, rechazaron o instrumentalizaron. 
de Chile que fueron consideradas en función de tres criterios básicos: existencia, referencia a delitos de connotación sexual y estado de conservación. Los documentos representan el $35 \%$ de los delitos violentos registrados en la zona en el siglo XIX e incluyen 52 denuncias de violación, 50 casos de rapto y 16 de estupro.

En más del $50 \%$ de los casos, las víctimas fueron jóvenes adolescentes -a veces púberes-, pertenecientes a Arauco, Maule y los sectores aledaños a la urbe de Concepción. La mayor parte de los casos evidencian correlación entre la perpetración del delito y predominio de la ruralidad como condición de vida de los sujetos involucrados, dejando al descubierto algunas de las complejidades derivadas del acceso a la justicia y los alcances de la institucionalidad dispuesta para su administración en estos espacios y sus poblaciones. Pese a ello, la documentación consultada da cuenta de sujetos con capacidad de agencia para movilizar y movilizarse en torno y a través de las prácticas e instituciones de justicia de la época (Albornoz 2013: 106).

Considerando que la historia de la violencia y la criminalidad es también la historia de las relaciones entre el poder, la sociedad y los sujetos, mediadas por el derecho (González 2012: 89), aquí se entiende la violencia como un complejo relacional múltiple que permite reconocer la expresión de los conflictos y contradicciones que afectan a una sociedad en un tiempo dado, las actuaciones violentas de los sujetos y las legitimaciones culturales e ideológicas dadas a su uso - a nivel estructural y simbólico-, expresadas en el funcionamiento de las instituciones y la aplicación de los cuerpos normativos que las regulan (Goicovic 2013: 11 y 2004: 121-145).
En base al análisis de casos, aquí interesa por una parte determinar la ocurrencia de delitos sexuales y sus alcances dentro de la comunidad enunciada; en tanto que, por otra, importa reconocer las congruencias y probables contradicciones entre discursos y prácticas en cuanto al proceso de judicialización y criminalización de los hechos de violencia sexual según los marcos regulatorios vigentes. Ello, entendiendo que, tras el funcionamiento de la institucionalidad y el despliegue de las prácticas de justicia, estas y sus agentes constituyeron también un reflejo de la visión que la sociedad en su conjunto tuvo frente a temas como la valorización de la mujer y sus roles, y el uso de la violencia y la connotación dada al abuso físico y sexual en su contra (Fries y Matus 1999: 139-143).

Particular interés guarda para nosotros el uso de la fuerza en y sobre el cuerpo femenino como espacio de producción y proyección de un sistema de significación cultural (Tuñón 2008; Le Bretón 1999), en que dicho cuerpo constituyó en más de un sentido-, un receptáculo de las tensiones, desigualdades y contradicciones respecto de la mujer, en tanto sujeto/objeto y cuerpo físico/cuerpo social dentro del espacio y comunidad en este caso estudiada (Albornoz 2009; Pérez y Ortega 2014) ${ }^{4}$. Lo expuesto, junto con evidenciar una valoración diferenciada de los sujetos frente al tema de la violencia en general, permite entender la interpretación y tratamiento dada a sus manifestaciones según la consideración de atributos como género, clase y etnia, entre otras variables (Vasallo 2005; Goffman 2006; Muchembled 2010).

Cada sociedad genera una lectura del cuerpo a partir de sus propios códigos, por lo que la forma en que éste se valora, está determinada históricamente por un conjunto de variables no siempre evidentes, pero si presentes. El cuerpo y sus representaciones es entonces una construcción social. 
En el caso de Concepción, lo anterior, junto con dar cuenta del fenómeno, también evidencia diferencias en términos del trato y resultados obtenidos de la aplicación de justicia en los hechos de abuso y/o atentados sexuales según las características de los implicados en las causas y la valoración de sus cuerpos (Gil Ambrona 2008; Le Bretón 1995). Diferencias particularmente evidentes en aquellos casos en que a la precariedad material y de capital cultural de las víctimas se sumaron otras variables como la ascendencia étnica de sus protagonistas ${ }^{5}$.

Para la época analizada, la ciudad de Concepción, así como su área geográfica y administrativa, constituían un importante nodo de población, poder y recursos en Chile. No obstante, su condición de espacio con un alto porcentaje de población dispersa, de origen mestizo o indígena -en su mayoría desarraigada y rural-, tornaron en más de un modo compleja la acción de autoridades e instituciones, tensionando su eficiencia en términos de resultados en el tiempo (León Solís 2007; Rojas Gómez 2008; González 2011).

Los esfuerzos de las elites, en aras de garantizar la hegemonía de un discurso arraigado en el conservadurismo, resultaron igualmente complejos frente a la amalgama de influencias que tempranamente facilitaron el desarrollo de formas de sociabilidad alternativas, marcadas por la espontaneidad y el uso de la violencia como medio de obtención de resultados o solución de diferencias; hecho que la autoridad

\footnotetext{
Aunque no es posible establecer generalizaciones, dentro del corpus analizado en aquellas causas en que las afectadas fueron de origen mapuche, los resultados de los procedimientos terminaron por desestimar la gravedad del delito, cambiar su tipificación, sobreseer los procesos o liberar de responsabilidad a los inculpados cuestionando de paso la moralidad y calidad de vida de las víctimas.
}

interpretó como una amenaza, al tiempo que una demostración de la ausencia de moralidad atribuida a algunos sectores de la sociedad expresada en la frecuencia con que éstos incurrían en alguna forma de transgresión o violencia (León León 2015; González 2012). Al respecto, $R$. Salinas ha sostenido que en Chile, como en la mayoría de los espacios americanos, las culturas originarias y la sociedad cristiana occidental tempranamente entraron en una profunda contradicción respecto de tópicos como la sexualidad, la familia y el matrimonio (Salinas 1995: 1-20). Así, mientras las primeras favorecieron la proliferación de uniones libres de manera espontánea y/o violenta, la segunda validó la familia monogámica y el matrimonio como única forma de relación admisible entre los géneros (Salinas 2010; Escriche 1838), condición que en Chile tuvo como principal efecto el control disciplinario sobre el cuerpo, con énfasis en el dominio moral y jurídico sobre las conductas femeninas (Le Bretón 1992; González 2011).

Por su parte, y frente a este tema, J. Collyer ha postulado que la concepción de sexualidad en Hispanoamérica fue definida a partir de la tensión y contradicción entre un ideal mariano fuertemente arraigado en el imaginario de la virtud sumisa de lo femenino y una identidad sexual masculina basada en la idea de la exclusividad del derecho a posesión del macho sobre la hembra (Collyer 2010: 10). Este hecho sumado a otras variables, derivó en la legitimación de un esquema de relaciones cruzado por la violencia y la subordinación de la mujer que permeó profundamente el sistema de relaciones entre los géneros dentro de nuestras sociedades. Lo anterior también permite comprender la noción de normalidad otorgada a ciertas prácticas como medio de sometimiento de la voluntad y conducta femenina a los deseos 
masculinos en lo doméstico y privado, así como al mandato del resto de la sociedad y del propio Estado en lo público (González 2011: 130). En este contexto, norma y justicia aparecen como una arista más de la tensión social expresada en la existencia de culturas legales y códigos morales diferenciados según los sujetos sobre los que operó, cuestión a nuestro juicio evidente en materia de delitos de connotación sexual (Armand-Duc 1993: 109 y ss).

De modo complementario, el hecho de que en América fuesen aplicados un conjunto de principios normativos inspirados en la realidad Europea, y a contrapelo de las características culturales y los comportamientos sexuales de las poblaciones locales, profundizó la brecha de la justicia en desmedro de las mujeres, exponiéndolas tempranamente a vicios $y$ prejuicios en materia de defensa frente a los excesos de los que llegaron a ser objeto, entre los que se cuenta -claro está- aquellos de connotación sexual (Rojas Gómez 2008: 20).

Historias como las reunidas en este trabajo, junto con evidenciar la existencia de un fenómeno complejo de características estructurales y transversales, también constituye la síntesis de aquel tipo de violencia simbólica que, expresada en el daño físico al cuerpo femenino y la mácula sobre su "honra", tensionó a la sociedad y sus instituciones frente a las querellas de quienes, como en el caso de María y Catalina, demandaron reparo y justicia (Farge 2008: 22 y ss) $)^{6}$, visibilizando de paso las contradicciones de la sociedad, los sujetos y su tiempo.

\footnotetext{
La expresión del sufrimiento, la violencia, las quejas, son variables que desde la historia deben ser atendidas, desentrañando los lenguajes, sentidos y objetivos de sujetos ordinarios que enfrentados al poder letrado, dan cuenta de sus penas, sus rabias, lágrimas y pérdidas, pérdidas.
}

\section{2. "Las heridas mencionadas no pueden ser causadas sino por haberse cometido el acto de estupro en la niña". Las pruebas, el delito y los vaivenes de la justicia}

En el caso de Catalina, y quien presenta la demanda -su madre putativa ${ }^{7}$-, el empeño estuvo en probar la gravedad de los hechos en función de cuatro elementos: el daño físico y moral propinado a la víctima, la minoría de edad de la afectada como agravante del delito, la reclamación de justicia en contra del victimario y la configuración de un testimonio de prueba basado en informes, peritajes médicos y policiales avalando la gravedad del delito perpetrado (Foucault 2014; Rojas Gómez 2008).

A diferencia de otros casos observados, esta demanda no buscaba alcanzar un acuerdo extrajudicial, tampoco reparación económica, sino el encarcelamiento y castigo del ofensor ${ }^{8}$. María Juana Leal forma parte de aquel conjunto de sujetos que sin poseer una cultura letrada, y probablemente desconociendo en detalle el contenido exacto de la ley, recurre y demanda

De acuerdo al Diccionario de Autoridades, el concepto "putativo" designa al "reputado o tenido comúnmente: y así se dice padre putativo, hijo putativo" (Tomo V, 1737). La expresión "madre putativa" era empleada para designar una práctica habitual de adopción informal de niños para su crianza. Por lo común este sistema operó como una estrategia de sobrevivencia empleada por familias con una prole numerosa y con escasas posibilidades de sustentación económica. Aunque esta práctica implicaba la generación de lazos de dependencia y afecto entre las partes, muchas veces facilitó el encubrimiento de prácticas de explotación y abuso consentido de menores. En la causa analizada, éste no fue el caso. En más de una alusión, el documento deja al descubierto una relación de afecto entre María y Catalina, cuestión que torna aún más rica la fuente.

8 Enalgunos delos expedientesanalizados, asistimosalaconciliación de acuerdos reparatorios entre las partes, ello como parte de una dinámica de justicia negociada que, evitando los procedimientos y costos de la administración de justicia, conformaba a las partes según sus objetivos. Tales compensaciones iban desde el pago de dineros, hasta el encubrimiento de la deshonra a través del matrimonio. 
justicia en favor de su hija adoptiva, en lo que fue una actitud cada vez más frecuente entre los diferentes sectores de la sociedad a lo largo del siglo XIX (Bravo 2015; Undurraga 2010). Esto obliga a considerar la capacidad activa y operativa de los actores sociales en función del marco cultural en el que se encontraban insertos (Cornejo 2007: 251-2) ${ }^{10}$, especialmente a la hora de evaluar los límites y el impacto de sus acciones al usar, manipular e interpretar en su favor las normas $\mathrm{y}$, por cierto, las prácticas de justicia (Undurraga 2010: 60-87).

Volviendo al caso que nos ocupa, cuando María decide denunciar la violación de su hija, espera que las instituciones funcionen en conciencia de que esa es la forma en que una mujer de su estrato, condición y recursos puede resarcir los daños infringidos a Catalina (Albornoz 2007: 17-8). Estos hechos obligan a evaluar la fuente no solo en sus formas, sino también en cuanto a los lenguajes empleados en ella a la hora de presentar los sucesos en el marco de una justicia a la cual se aspira. En tal sentido, el dramatismo empleado en las descripciones, la alusión a los excesos, los lamentos, las pérdidas, todo, forma parte de una puesta en escena que no

El aumento de las denuncias observado en los fondos documentales del periodo, si bien da cuenta de una extensión en el uso de procedimientos judiciales, no implica necesariamente un aumento de confianza de los sujetos en el funcionamiento y los resultados de las prácticas de justicia, pues a la par de éstos, siguieron operando formas de mediación privada de los conflictos. En ocasiones una demanda operaba como un elemento de presión que obligaba a una de las partes o a ambas a negociar hasta alcanzar tales acuerdos. Este hecho también encuentra explicación en el progreso de la sistematización de registros escritos, la profesionalización de los funcionarios de justicia y la evolución del sistema judicial y penal en Chile conforme se avanzó en la centuria.

10 Se ha considerado en este texto la idea del testimonio judicial como una suerte de "fianza sociocultural", cuya estructura se encuentra culturalmente normada y resultará condicionada por las herramientas de que dispongan los sujetos para dar sentido a sus testimonios. resulta ingenua ni neutral (Foucault 2014; Farge 2008). En tales descripciones, la inminencia de los detalles importa y es necesaria en cuanto recurso argumentativo que busca impactar y movilizar a testigos y jueces, y a la propia comunidad, en la orientación de los procesos y sus resultados (Foucault 2005: 20 y ss.). Así, en su querella, María junto con invocar un derecho también se sirve de un medio y sus dispositivos con un fin: la justicia.

La materialidad adquirida por el conflicto en la demanda expone las redes de poder, visibilizando las solidaridades, discursos y sentimientos del sustrato cultural de los sujetos, figurándolos como agentes no pasivos dentro de un sistema (Albornoz 2007: 17-55) ${ }^{11}$. Esto figura el derecho y la justicia como un puente y como parte de un engranaje que, a través de los discursos de las partes involucradas, buscaba unir un concepto de realidad con la alternativa imaginada sobre ella a través de una narrativa conocida y validada social e institucionalmente respecto de la justicia (Cover 2002: 23). En el sumario expuesto, una primera señal en esta dirección estuvo en la exposición de los hechos. María no calla ni oculta lo sucedido, más bien espera que la tragedia de Catalina sea conocida y reconocida por las autoridades y la comunidad, las lesiones certificadas por un médico (juicio profesional de prueba), y el delito ratificado por la autoridad policiaca de turno. En palabras de M. Albornoz, María es una de esas mujeres con sangre en las venas y aire en la cabeza que incomodan al sistema, generando ruido desde su interior y no al margen de él (2013: 76).

Se alude aquí a las ideas expuestas por la autora respecto a la existencia de una "justicia viva" perceptible a través de los expedientes en la acción de los funcionarios, pero también de la acción de los "justiciables", quienes reclaman, se quejan, suplican, exigen y piden. 
Desde la perspectiva de los procedimientos, en la configuración del caso, la mirada del perito médico constituía una pieza fundamental, pese a que muchas veces éste terminaba por rebasar los límites de su función técnica para dar cabida a subjetividades respecto de la calidad moral de las víctimas, impactando negativa o positivamente en los peritajes $y$, por cierto, en la administración del proceso y sus resultados (Estrada 2010). En nuestro caso, la verificación de las lesiones de Catalina no hizo más que ratificar que la "niña Catalina...no presenta heridas, sino una ruptura seria ocasionada del himen, e igualmente está roto el perineo ${ }^{12}$ como cuatro líneas de ángulo posterior para atrás", descripción tras la cual el perito sentenciaba que "las heridas mencionadas no pueden ser causadas sino por haberse cometido el acto de estupro en la niña" (ANS, FJC, Leg. 193, exp. 28, fjs1-25) ${ }^{13}$. De acuerdo al peritaje, el delito existía, restando por establecer las circunstancias en que este había ocurrido, un hecho fundamental considerando que el asalto tuvo lugar en ausencia de testigos.

12 El orificio del perineo es la región anatómica correspondiente a piso de la pelvis. En la mujer, este se presenta como una zona triangular en la que por delante es posible reconocer la vulva y por detrás, el borde del ano, separados por un puente cutáneo. Entre la vulva y el ano se encuentra la zona fibrosa que constituye un elemento de soporte esencial de los órganos genitales internos, cuya destrucción o desgarro provoca el desplazamiento hacia el exterior de los mismos. Teniendo en cuenta esta definición, el informe médico emitido en el caso de Catalina, daba cuenta de la perpetración de una violación brutal.

13 Dentro del Diccionario de Autoridades, el estupro es definido como el "concúbito y ayuntamiento ilícito y forzado con virgen o doncella (...)". Acto seguido la definición consigna que "Pecar con soltera es simple fornicación; con casada adulterio, con doncella virgen estupro, con parienta incesto, con persona Religiosa y dedicada a Dios sacrilegio o adulterio espiritual". (Tomo III, 1732). Sobre el mismo concepto, J. Escriche distingue la definición jurídica del juicio médico, según el cual "estupro en su sentido propio y riguroso no es más que la violenta desfloración de una doncella (...)". (Escriche 1874:632).
Pese a su proximidad geográfica de Concepción, Chepe era un pequeño enclave de casas y ranchos cuya población puede ser definida como rural y de escasos recursos; en esencia, un sector periférico, donde los sujetos se conocían unos a otros identificando con facilidad a los afuerinos, a quienes solían responsabilizar de los hechos de violencia que de cuando en cuando alteraban la cotidianidad del lugar ${ }^{14}$.

Para esta época, y pese al desarrollo urbano, la ruralidad y dispersión de las poblaciones continuaba siendo un rasgo dominante en Chile y en la zona estudiada, lo que en el caso de las mujeres, junto con dotarlas de ciertos márgenes de libertad, también las hizo vulnerables a eventuales abusos de carácter sexual (Goicovic 2006: 21). Estos rasgos permiten entender la dinámica del trato entre los miembros de la vecindad, al tiempo que explican la existencia de prejuicios y ciertos códigos de solidaridad que incluían el auto cuidado entre sus miembros, así como la existencia de mecanismos de regulación que "desde abajo" buscaban mantener o recuperar los equilibrios internos frente a los hechos de violencia evitándolos o procurando su sanción, fuese por la vía institucional o comunitaria (Mantecón 2014; Undurraga 2012) ${ }^{15}$.

En el caso analizado Catalina conocía a su agresor, cuestión que otorgaba mayor gravedad

\footnotetext{
Pese a la creencia popular, en el caso de los delitos de connotación sexual, más que por extraños, éstos solían ser perpetrados por conocidos o familiares debido a la facilidad de acceso a las víctimas.

15 Según T. Mantecón, el disciplinamiento social tuvo proyecciones desde las sensibilidades de la gente común, impactando en los resultados de los procesos de cambio social, cultural y político y por cierto en las prácticas y usos de la justicia. Esto es lo que el autor identifica como disciplinamiento "desde abajo".
} 
jurídica y social al evento, pues no se trataba de un desconocido, menos aún un afuerino. El ataque a Catalina constituía un "delito de oportunidad", agravado por la ventaja del conocimiento previo de la víctima (Riva 2014: 285-316) ${ }^{16}$. Desde el punto de vista comunitario, la idea del enemigo interno perturba y obliga a sus miembros a reaccionar con presteza reparando los daños y evitando su reiteración, sea recurriendo a las instituciones -como en este caso-, sea tomando la justicia por mano propia, como en otros hechos (Undurraga 2014; Agüero 2008).

En una primera declaración, Catalina expresaría que al momento de ser atacada "(...) estaba yo sola en casa de mi madre putativa o adoptiva (...)", circunstancias bajo las cuales, el acusado había llegado a "pedirme un lazo", acto que habría aprovechado para cogerla del vestido por detrás y "(...) sin decirme nada me tendió por fuerza de espaldas y comenzó a forzarme" (ANS, FJC, Leg. 193, exp. 28, fjs1-25). La clave de su versión de los lamentables sucesos estuvo en la descripción de la resistencia ofrecida a su atacante. Frases como "(...) yo gritaba con todas mis fuerzas pero nadie ocurrió a mi apuro", se orientaron en esa dirección. No obstante su oposición, el relato finalmente sentencia “(...) José Cruz Soto consiguió su instinto dejándome enferma" (ANS, FJC, Leg. 193, exp. 28, fjs1-25).

La descripción es contundente al tiempo que da cuenta de varios rasgos comunes a

16 Se usa la denominación de "delito de oportunidad", para aludir a la perpetración de un ilícito aprovechando las circunstancias o un conocimiento mínimo entre víctima y victimario. Según el Código de Procedimiento penal de 1874, una agravante de la responsabilidad criminal en la ejecución de cualquier delito era la actuación sobre seguro, la premeditación y el empleo de astucia. Ver Libro I, Título $1^{\circ}$, art. 12, incisos 1 y 5 . Código Penal, Imprenta de la República, de Jacinto Muñoz, Santiago de Chile 1874. otros relatos frente al mismo tipo de delito: la indefensión facilitada por el aislamiento del rancho, la soledad de las víctimas y la ausencia de testigos, así como el desequilibrio de poder y fuerza entre la víctima y su atacante ${ }^{17}$.

El uso de expresiones como "yo gritaba con todas mis fuerzas" o, "nadie acudió en mi auxilio", no son casuales, antes bien responden a una lógica argumentativa conocida. Dentro del juicio comunitario, al igual que en la evaluación desde lo jurídico, estos delitos exigen y esperan la oposición de la víctima, aún a costa de su propia integridad, en defensa de su honra y de su fama (Sedeillán 2009; Undurraga 2004). En tal sentido, y vencidas las fuerzas físicas, el grito podía llegar a constituir un arma poderosa empleada para descolocar al agresor, motivando el auxilio de terceros y otorgando publicidad a un acto que buscaba quedar en la impunidad (Estrada 2010: $5)^{18}$. En su relato, Catalina agregaría la pérdida de conciencia, condición reconocida dentro de las leyes como agravante en la perpetración de este tipo de delitos (Cód. Procesal Penal 1874: Art. 361. 1). La frase "me desmayé quedando sin sentido" no deja dudas sobre la brutalidad irracional del asalto, pero además alude a un último arrebato de defensa: la negación de

17 El artículo 361 del Código Penal de 1874 reconoce el delito de violación asociado a tres causales a) cuando se accedía a una mujer haciendo uso de fuerza, b) si la mujer en cuestión se encontraba privada de razón y c) cuando la víctima era menor de 12 años, diferenciando así el delito de violación del de estupro. Este último fue entendido como el acceso carnal con mujer mayor de doce y menor de veinte (Código Procesal Penal. Libro II, Sección VI, art. 363).

18 En 1864, en el sector de Cancha Rayada, próximo a Coronel, Gertrudis Astudillo fue atacada y violada por Cipriano Gaete. En su relato Gertrudis dijo que intentó pedir auxilio gritando, más no pudo avanzar en su empeño porque su atacante "le empezó a apretar el pescuezo, viéndose en este estado la declarante, no podía gritar ni hacer la menor acción para defenderse, con este motivo el citado Gaete logró hacer todo lo que quiso en el cuerpo de la declarante, hasta llegar al extremo de consumarse el delito de violación" (ANS, FJC, Leg. 159, pza. 4, fs. 4 y 5). 
la realidad, en lo que interpretamos como un arranque de impotencia de la víctima frente a la embestida de su agresor (Tausiet y Amelang 2009: 7-31)19: "(...) al momento de separarse me desmayé quedando sin sentido, votando mucha sangre: el médico me ha reconocido y el podrá decir en la forma como me dejó Soto" (ANS, FJC, Leg. 193, exp. 28, fjs1-25). En este punto se advierte el uso de una forma narrativa que compromete el juicio médico como prueba del delito y confirmación de su estado.

La exposición de estos elementos advierte una arista política y a la vez ritual en la demanda que buscaba trascender el hecho individual de violencia para elevarlo a una dimensión comunitaria a la que en general se apela dentro de las reclamaciones de justicia en estos delitos (Undurraga 2012: 21-32). Dentro de este juego textual y gestual, las referencias al "honor perdido" o la "honra estropeada", evoca gestos y remite a significados que evidencian una base común: ser un elemento de definición de identidad y status de los sujetos dentro de la sociedad y/o comunidad, por lo que su vulneración dota de legitimidad las querellas, el derecho a justicia y a desagravio de la víctima y su entorno, validando inclusive acciones de venganza individual (Candau 2014; Undurraga 2008; Albornoz 2007).

Si desde la perspectiva de las demandantes, el empeño en la configuración de la causa estuvo focalizado en el reconocimiento de la afrenta, la violencia y el daño moral y social provocado; en el caso del acusado, dicho esfuerzo se concentró en la relativización de la gravedad de

19 Desde la teoría de las emociones, estados como el temor, la rabia, la impotencia, la tristeza, pueden gatillar reacciones físicas como el rubor del rostro, las lágrimas o la pérdida de conciencia, como en el caso descrito. los hechos a partir del traspaso parcial o total de su responsabilidad a la parte acusatoria (Undurraga 2008: 208-236). Esta era la forma más común de defensa de los implicados en estos casos, en lo que constituía una nueva forma de violencia hacia las víctimas. De allí la importancia de visualizar estos actos en función de sus contextos, ampliando el análisis a la evaluación de la experiencia desde quien la ejerce y quien la experimenta; hecho que implica entender por una parte la violencia en plural y, por otra, la ausencia de total ingenuidad en sus protagonistas en términos de sus discursos y uso de la justicia (Albornoz 2013: 76-79).

Este mundo de representaciones también remite a prácticas que incluyen la construcción de un imaginario sobre lo justo y lo injusto a partir de las resistencias y acomodos entre las partes en tensión (querellante y querellado), los imaginarios sobre la justicia y las normas que finalmente lo regulan. Un escenario donde la fuerza de la palabra como testimonio de memoria resulta esencial, especialmente cuando se considera que en estas formas de delito, el bien tutelado jurídicamente resulta ser la integridad sexual, pero sobre todo la honestidad moral de la víctima (Sedeillán 2009: 122). En este sentido, y tal como expresa $A$. Araya, el sistema judicial y sus procedimientos funcionan como una fábrica de historias de distinta naturaleza e impacto textual (2007: 185-218), donde mientras unos recurren a una justicia institucional y hegemónica, otros aspiran a una justicia negociada (Undurraga 2012: 64) ${ }^{20}$.

\footnotetext{
- En 1838, Epunocemo Gutiérrez sedujo y estupró a Francisca Rodríguez. La formulación de una promesa de matrimonio permitió al acusado evadir su responsabilidad en los hechos, en tanto que la consumación del matrimonio limpió la deshonra de Francisca. El acuerdo de materialización de la unión entre el demandado y la demandante fue mediado por la madre de la víctima. ANS. FJC, 1838, Leg. 158, pza. 4.
} 
En cualquiera de estos escenarios, los sujetos usan estrategias, las diseñan o se sirven de las ya existentes en función de sus objetivos.

José Cruz Soto (el demandado) ${ }^{21}$, por su parte expresaría que nunca antes había estado preso, y "(...) ahora lo estoy por haber tenido acto carnal con la niña Catalina Márquez que tendrá como doce años de edad".

La referencia a la edad de la estuprada, difiere de lo declarado por la demandante en lo que pudo ser una estrategia tendiente a restar gravedad a los hechos. Resulta probable también que, en la elaboración de estas argumentaciones, la presencia de un abogado defensor (José García) marcara una diferencia en la orientación de las declaraciones del acusado, basado en las directrices técnicas entregadas por este último a partir de su conocimiento de la ley y la evaluación de sus resquicios en favor de su defendido. De igual modo, al referir como motivo de su prisión el "(...) haber sostenido acto carnal" con la demandante, Cruz Soto relativiza la violación dejando entrever la probabilidad de un acceso consentido por la joven:

Principié a hablarle para que se entregase a mí y le pasé cuatro reales, pero no quiso recibirme un centavo: yo insistí en que cediera a mis deseos aunque sin resultado hasta que le ofrecí casarme con ella: Cuando le hice este ofrecimiento, entonces la Catalina consintió en entregarse a mí y yo le usé teniendo acto en ella siendo la niñita doncella. Durante el acto no lloró, sino cuando yo me separaba de ella, no he violado por consiguiente a la dicha Catalina, sino que he tenido acto con ella, por haberse prestado voluntariamente por interés del casamiento que yo le prometí y que yo estoy dispuesto a cumplir (ANS, FJC, Leg. 193, exp. 28, fjs1-25). de Lautaro, según los datos aportados en el expediente.
Llamamos aquí la atención sobre tres elementos del relato: promesa de matrimonio, acceso voluntario a la víctima y reconocimiento del estado de doncellez de Catalina. Los dos primeros buscaban relativizar la gravedad de la acusación a partir de un posible cambio en la tipificación del delito (Escriche 1874: 652655) y, eventualmente, la desestimación del uso de violencia física, basado en la presunción de consentimiento de la víctima. Aquí la palabra empeñada, en una supuesta promesa de matrimonio, abría el caso a una posible conciliación a partir de la compensación moral a través del matrimonio (Candau 2006: 179$182)^{22}$. De ser cierta la promesa y la disposición del acusado a cumplirla, la demanda se abría a una eventual solución, extinguiendo así la responsabilidad penal del demandado por la vía del acuerdo y el perdón $(\mathrm{CPCH}, 1874$ : Libro I, Tít. V, Art. 93. 5). Asimismo, y dada la minoría de edad de Catalina, la decisión sobre un eventual acuerdo de esta naturaleza no pasaba por ella; ni siquiera por la voluntad de su madre de crianza, sino por la de sus padres biológicos según lo dispuesto en el Código Civil $(\mathrm{CCCH}, 1885$, Tit. IV, art. 107 y 108), concordante con la mayor valoración de la sangre por sobre los afectos en la ley y la administración de la justicia.

Se cree con mucha probabilidad que Catalina Vásquez tenga a la fecha doce años cumplidos y para justificar este hecho se hacen diligencias para encontrar su fe de bautismo. Teniendo pues 12 años cumplidos, como apta

\footnotetext{
Aunque el Código Civil en su Tit. II, art. 98 estipulaba sobre las promesas de matrimonio que "No se podrá alegar esta promesa ni para pedir que se lleve a efecto el matrimonio, ni para demandar indemnización de perjuicios", hemos visto dentro de la documentación la invocación de promesa como una excusa para alcanzar acuerdos de reparación en los actos de violencia sexual, seducción o estupro. En más de un caso también, la demanda de su cumplimiento fue una usada como reparación entre las partes en litigio. Con probabilidad y en conocimiento de esta estrategia, José Cruz Soto y su defensa vieron en este medio una probable solución a la controversia.
} 
para el matrimonio según el ritual romano, ya no habría inconveniente para su celebración previo consentimiento de su padre que vive actualmente en Arauco (...) el reo Soto se compromete a comprobar en forma legal que su padre consiente en el matrimonio, así que su hija cumpla la edad", junto a lo cual se obligaba "a dar una mesada a la niña Vázquez así que obtenga su libertad (...) hasta el día en que se verifique el matrimonio (ANHCh, FJC, Leg. 193, exp. 28, fjs1-25) ${ }^{23}$.

Por otro lado, el reconocimiento del estado virginal de Catalina se orientó a mitigar las consecuencias del acto culposo, pues en este caso y dada la contundencia del peritaje médico, era imposible sostener un discurso alternativo. En cualquier escenario, queda de manifiesto que tanto María, como José y su defensor, reconocen y usan lenguajes, estructuran discursos y los dotan de significado en función de sus respectivos objetivos y posición dentro del sistema (Mantecón 2014: 173). La pregunta es hasta qué punto la justicia y sus agentes fueron capaces de abstraerse del juego, para actuar conformes a la ley (Brangier 2014: 38).

Ante la duda sembrada por Cruz Soto, era imprescindible acreditar la integridad moral y buena fama de la víctima (Undurraga 2004: 1735), quien al ser requerida frente a los nuevos antecedentes aportados por el demandado, respondería a los dichos de Cruz Soto sosteniendo que:

(...) no le ofreció ninguna cantidad de dinero ni menos casamiento pues que la tomó de repente y por fuerza le puso de espaldas para violarla como lo hizo y lo que tiene declarado es la verdad. ... dijo ser de edad de diez años y no firmó esta declaración por no saber (ANHCh, FJC, Leg. 193, exp. 28, fjs1-25).
Dentro del relato del demandado las expresiones "principié a hablarle para que se entregase a mi", o "yo insistí en que cediera a mis deseos aunque sin resultado", nos hablan de un sujeto persistente, un seductor o un pícaro que no evade su participación en los hechos, aunque sí la connotación de violencia que se les quiere imprimir por las demandantes en la querella. Un comportamiento por lo demás absolutamente congruente con los atributos básicos de virilidad reconocidos socialmente en la época (Goicovic 2006: 75-80).

Fuese una práctica inconsciente, o el desarrollo de una estrategia premeditada, lo cierto es que, en este caso los efectos de este discurso jugaron por un tiempo a favor del acusado, tiempo empleado por éste y su defensa para insistir en la moción del matrimonio y la concertación de un acuerdo entre las partes.

Pese al empeño del acusado y su defensa, finalmente las autoridades fallaron en favor de la demandante. José Cruz Soto fue acusado de violación y estupro forzado, y condenado a cumplir una sentencia de veinte años de presidio con destierro en la cárcel de Arauco, espacio próximo a la frontera. En cuanto a la palabra de matrimonio, el tribunal desestimó la propuesta, atendiendo a que la corta edad de Catalina y su condición de doncella (Escriche 1874; Partida VII, Leyes 19 y 20). Ambas variables hacían del delito cometido por Soto, un hecho grave, imposible de no castigar del modo más severo, a modo de ejemplo y escarnio frente a otros eventuales de similar naturaleza.

Debe recordarse que María es la madre de crianza o putativa de Catalina por lo que legalmente y como menor de edad, la decisión sobre un probable matrimonio o el consentimiento sobre cualquier forma de acuerdo entre las partes compete, en principio a los padres biológicos, y de modo más concreto, al padre. 


\section{Las otras Catalinas.... Las víctimas silentes de la violencia sexual.}

En el siglo XIX las instituciones y agentes de justicia, buscaron sistemáticamente alejarse de las normas coloniales a objeto de garantizar la legitimación de las instituciones, los procedimientos y agentes de la justicia, aumentado así el control sobre los grupos sociales. Pese a ello, en muchos aspectos tales prácticas siguieron ancladas en aquel pasado y sus marcos regulatorios (Brangier 2011: 1-8 y 2013: 1-33).

En el caso de la violación, ésta fue entendida como el acto de fuerza ejercido sobre la mujer contra su voluntad, implicando en ello la consumación de la cópula sexual. La legislación vigente en Chile (Brangier 2014; Albornoz 2004) otorgaba mayor mérito a aquellos casos en que, a partir de la penetración del miembro masculino, existía consumación de la cúpula, hecho considerado de mayor gravedad si la víctima era virgen (Araya 2006: 349 y ss.). La estimación de la virginidad como agravante de la afrenta solía dejar expuestas a una ambigua situación a quienes, por sus formas de vida y los patrones de violencia empleados en su contra, no cumplían con los requisitos previstos por la ley (Undurraga 2004; Escriche 1874). En estos casos, la sola tipificación de las agresiones solía ser cuestionada, dificultando la prueba y, por cierto, el castigo de los culpables (Ramos 2008: 74). Así ocurriría en el caso de la niña Pascuala, quien pese a ser estuprada por Justo Yáñez, nunca pudo acreditar el delito, pues de acuerdo al informe médico las lesiones ocasionadas correspondían a aquella propias de una mujer de "mala vida" (ANS, FJC, 1849, Leg. 203, pza. 7).

Resulta interesante reconocer en este ejemplo, y otros de similar naturaleza, el modo en que la ley normaba el carácter de la experiencia sexual de la mujer y la forma en que ésta pudo o no llegar a perder su virginidad, como un atributo físico, simbólico y cultural en que se proyectaba la integridad moral de la sociedad. Resulta obvia también la clara contradicción de sociedades que expusieron a mayores vulneraciones frente a estos hechos precisamente a las mujeres. En el caso aludido, Pascuala es reducida a la calidad de "mujer de mala vida", restando validez a su condición de víctima vulnerada y probablemente abusada en más de una ocasión por Justo Yáñez u otros hombres antes que él.

La legislación vigente, además, establecía una serie de diferencias, según a quién y en qué condición acaecían los hechos. Si la víctima era de corta edad, la violación solía ser asimilada al delito de estupro, aunque tal asociación tampoco fue garantía de justicia. La causa de Juliana Inojoza constituye un ejemplo de ello. Natural de la localidad de Hualqui, Juliana fue estuprada a sus escasos ocho años en enero de 1864, por Miguel Tiznado y un desconocido. En su caso, la ausencia de desfloración impidió la aplicación de castigo al único imputado en la causa, pues el segundo se dio a la fuga. Al igual que en la causa anterior, el peritaje médico si bien confirmó la existencia de abuso, no permitió sustentar la tesis de la violación pues "el himen de la niña permanecía intacto" (ANS, FJC, 1864, Leg. 194, exp. 8, Fja. 22).

\footnotetext{
Del examen practicado resulta: que la niña no ha sido estuprada, pero sí padece irritación de carácter venéreo y un flujo blanco procedente de la vagina y uno del intestino recto, de un olor nauseabundo y bastante abundante. Todo esto junto con la hinchazón, dolor y sangramiento de las partes, lo que indican ser una infección venérea (....). Dicha infección pudo haber sido contagiada por uno de los dos hombres que la tocaron con el pene (ANS, FJC, 1864, Leg. 194, exp. 8, Fja. 22)
} 
Tanto o más grave fue el caso de Tránsito Lincopan, ocurrido en Arauco en enero, casi a fines de la centuria. Violentada sexualmente por Pedro Millaquín y Pablo Lepillan, el asalto siendo denunciado a las autoridades por su hermana Rosa. Aunque ambas mujeres fueron abusadas, en la apreciación de Rosa (la denunciante), su condición de mujer adulta, madre y con una vida sexualmente activa, hacía menos admisible su situación frente a la de su hermana Tránsito quien "nunca ha conocido hombre" (ANS, FJC, 1898. Concepción, Caja 65, pieza 14. Fja. 2).

Consciente de la diferencia de condición entre ella y su hermana derivada de la valoración social, moral y jurídica de su cuerpo y sexualidad frente a la de su hermana, Rosa se empeñó en avalar la gravedad del "estropicio" del que ha sido objeto Tránsito (Undurraga 2012: 200). En este caso, la gravedad de los hechos fue exacerbada por la extrema violencia empleada por los agresores, la que fue declarada por las víctimas y sus testigos, pues a diferencia de las causas anteriores, aquí sí los hubo. En el expediente, junto con el abuso sexual, fueron reconocidas otras agravantes como el uso de fuerza, amenaza de muerte y el robo con violencia:

Millanquin amarró de los brazos por atrás a mi tío Manuel Huaipan y a mi padre y además sacó para afuera a mi hermana, menor de edad, Tránsito y en un lado de la casa la violó. Lepillan también violó a mi hermana Tránsito en la cama de ésta y el que se quedó en la puerta, cuyo individuo no conozco su nombre (...), me tomó también por la fuerza y me violó igualmente. Estaba yo esa noche en casa con mis padres Ventura Lincopan y Juana Quedellanca, mi tío Manuel Huarapan, mi hermana Tránsito Lincopan y mi hijo Manuel Lepillan. De todos estos, yo con mi hermana y mi hijo conocimos perfectamente los dos asaltantes (....). Nos llevaron tres collares de plata, una cinta y dos medias lunas del mismo metal y varias especies incluyendo además diez pesos en dinero (ANS, FJC, Caja 65, pza. 14. fja 2).
Pese a las informaciones la violación tampoco fue acreditada. La razón, el informe médico de Francisco Sierralta, quien expuso que:

El himen o membrana de la vagina está desgarrada y sus colgajos forman, a la entrada de la vagina, un rodete que no está inflamado ni doloroso (...) no hay en los órganos genitales ni en sus contornos, ni contusiones, manchas de sangre, de pus o de esperma, ni otras señales que indiquen violencia.

De lo expuesto el infraescrito puede concluir:

$1^{\circ}$ que Tránsito Lincopan está desflorada, sin poder precisar la época en que esta desfloración tuvo lugar, $2^{\circ}$ que no hay señales actuales de violencia en sus órganos genitales y

$3^{\circ}$ que, en vista de segundo dato, no puede afirmarse que haya habido violación (...) (ANS. FJC., 1898, Caja 65, pza. 14, Fja. 5). ${ }^{24}$

La historia se repite una y otra vez, solo varía el contexto: niñas expuestas e indefensas, honras mancilladas, confianzas defraudadas por amigos, parientes y conocidos, asaltos fortuitos a manos de desconocidos, exposición y abandono voluntario o forzoso de menores, explotación laboral y abuso sexual, imposibilidad de auxilio ante el ataque.

Desde el punto de vista normativo, la proyección -hasta entrado el siglo XIX- de una tradición normativa aún marcada por la herencia colonial, sin duda afectó el desenvolvimiento de agentes y procedimientos encaminados a la aplicación de justicia. No obstante lo anterior, los sujetos en mayor o menor medida y con mayor o menor conocimiento del detalle y contenido de las normas se comportaron como agentes activos y con capacidad de desenvolvimiento y reacción dentro del sistema, pese a los resultados obtenidos ante sus querellas. Estas prácticas advierten el dominio de un conjunto de saberes que les permitieron diseñar estrategias, usar

El destacado es nuestro. 
recursos y elaborar argumentos a favor de sus diversos fines.

Desde el punto de vista institucional y de los agentes de justicia, la tensión entre una visión conservadora de la sociedad y las conductas de los sujetos fue aumentada por la configuración de una realidad marcada por la ocurrencia de actos de violencia de connotación sexual como los analizados en esta pesquisa. Este hecho, sumado a otros, así como la progresiva consolidación de las instituciones y el perfilamiento de un derecho alejado de la herencia colonial, conforme se avanzó en el siglo XIX, incidieron en la dinámica de los procedimientos de justicia y, por cierto, en la visión y valoración de la violencia y su uso en contra y sobre el cuerpo de las mujeres en el periodo analizado.

Nuestras fuentes, junto con dar cuenta de la existencia del fenómeno de la violencia sexual dentro de la sociedad de Concepción, nos han permitido aproximarnos al complejo mundo de las representaciones, prácticas y usos de la justicia dentro de un espacio regional.

Dentro de este escenario, las demandas por justicia, junto con dar cuenta el uso del sistema y sus procedimientos por los sujetos, también evidencia las tensiones de una sociedad frente a la valoración de los sujetos y las concepciones y usos de la justicia según diferentes atributos. En nuestro caso, el atributo elegido ha sido el género.

\section{Comentario final}

Frente a la constatación de una violación, siempre es posible advertir una evidente tensión entre la concepción del derecho, la valoración social de la víctima y el establecimiento de penas y castigos, cuestión frente a la cual los elementos de prueba podían ser morales o materiales.

En la primera categoría, la confesión -aunque fuese extrajudicial- o la jactancia del acusado, las declaraciones de testigos, las averiguaciones sobre la valía de las partes en conflicto, resultaban fundamentales. En tanto, eran consideradas como pruebas materiales y físicas los vestigios y señales del ataque, consistentes en la evidencia de desfloración, las lesiones sobre los órganos sexuales u otras partes del cuerpo (Estrada 2010:1-38). De allí el empeño, en los delitos de connotación sexual, en la constatación de laceraciones, fluidos y marcas como pieza fundamental para la configuración de la escena en que se acometía el asalto y en la que el cuerpo constituía el objeto de prueba.

Las declaraciones de testigos, y por supuesto los peritajes médicos, siempre fueron una pieza fundamental en la acreditación de los hechos (Araya 2014: 194-5), exigida por las leyes y reguladas por los procedimientos a cargo de los diferentes agentes de justicia. De acuerdo a estas variables, es admisible suponer que, en más de un caso, las víctimas de violencia sexual no alcanzaran a configurar los elementos de prueba suficientes para la acreditación del delito. Ante estas consideraciones, parece obvio que la situación judicial de aquellas mujeres que no cumplían con los requisitos previstos por la ley, fuese de mayor precariedad frente al sistema (Undurraga 2012: 64). En tanto, la gravedad e incluso la autenticidad de los hechos quedaba al arbitrio de la interpretación de los jueces, dependiendo de la naturaleza de las declaraciones de testigos, así como de 
la fuerza discursiva con que la propia víctima o su procurador defendiesen la causa, o de las impresiones que, en definitiva, víctima y responsable generasen en autoridades, facultativos médicos y la opinión pública (Araya 2007:48). Pese a esta dificultad, las fuentes accedidas en esta investigación dan cuenta de sujetos con capacidad de acción y decisión para demandar a sus atacantes y poner en movimiento el aparataje de justicia.

Esta evidente ambivalencia tampoco estuvo exenta del juego de intereses de cada una de las partes involucradas (Albornoz 2014; Brangier 2014; Mantecón 2014). Mientras algunos esperaban que la justicia actuara remediando el daño moral a las víctimas, otros deseaban lo mismo, pero por la vía de compensaciones materiales o económicas, y tampoco faltaron quienes trataron de evadir la justicia y borrar la afrenta cometida mediando la concertación de un matrimonio (González 2011: 340).

Bajo cualquiera de estas circunstancias, los sujetos escasamente pueden ser considerados como agentes pasivos dentro del sistema social y de justicia (Albornoz 2013: 78). Antes bien, de modo individual o colectivo, estos buscaron restablecer los equilibrios rotos, fuese a través del despliegue de estrategias que, mediante los procedimientos judiciales, les permitiesen alcanzar dicho objetivo, fuese a través de la puesta en escena de otros medios de negociación o mediación de la justicia (Araya, 2006: 349), sea a través de formas privadas de resarcimiento.

Los casos aquí analizados, nos hablan de sujetos que optando por la primera vía, se apropiaron de códigos, presionaron a funcionarios y agentes de justicia, aportaron informaciones y testigos, configuraron pruebas y estructurando discursos para demandar de las instituciones reparación dejaron al descubierto las tensiones y contradicciones de un sistema y unas prácticas que operaron de modo diferenciado según la calidad de las víctimas y los delitos perseguidos (Cobos 1985: 68).

Este trabajo ha profundizado en el estudio del delito de violación como una de las formas de violencia ejercida sobre el cuerpo femenino en el contexto de la sociedad tradicional chilena, dentro de un espacio regional, a saber, la provincia de Concepción en la segunda mitad de siglo XIX. En el desarrollo de estas reflexiones hemos entendido la violencia en plural (Albornoz 2013: 17-20) y como un complejo relacional (Goicovic 2004 121), a través del que es posible reconocer la expresión de las características, los conflictos y las contradicciones que afectan a la sociedad estudiada, a nivel estructural y simbólico, a través de las prácticas de justicia y del funcionamiento las instituciones y los cuerpos normativos vigentes (Palma 2014: 13-15).

La expresión del uso de fuerza en y sobre el cuerpo femenino da cuenta de la proyección de un sistema de significación cultural dentro del cual dicho cuerpo constituyó una suerte de receptáculo de las tensiones, desigualdades, conflictos y contradicciones, en tanto sujeto/ objeto, cuerpo físico/cuerpo social dentro del espacio y comunidad propuesta en este estudio (Albornoz 2009; Tuñón 2008; Le Bretón 1992).

En el caso de Concepción, nuestros hallazgos documentales constatan la ocurrencia de hechos de violencia de connotación sexual, física y simbólica hacia las mujeres, evidenciando rasgos de vulnerabilidad frente a los cuales 
se tensionó y demandó el funcionamiento de la institucionalidad y las prácticas de justicia. En ello, variables como la ruralidad, la precariedad material, la amalgama de culturas y las concepciones diferenciadas respecto el cuerpo, la sexualidad y el uso de la violencia como medio de satisfacción de objetivos y deseos fueron algunas de las causas que derivaron en la perpetración de delitos como los aquí analizados. Ciertamente, la constatación de violencia simbólica, expresada en el daño físico al cuerpo femenino y la mácula sobre su honra, a través del delito de violación, tensionó a la sociedad, las instituciones de justicia y sus agentes.

Una violación implicaba una herida cuya secuela quedaba impresa en la memoria de su víctima, pero también en la de toda una sociedad y una institucionalidad que no era capaz de proteger a sus miembros de la violencia. Las referencias "honras perdidas", evocaron significados que remiten, en sentido ritual, al sentido de vulneración comunitaria que de algún modo dotó de legitimidad el derecho a desagravio y la obtención de justicia empleada por quienes fueron sus víctimas (Candau 2014; Undurraga 2012).

Los actos de judicialización, así como las prácticas asociadas a la denuncia de abusos sexuales, suponen entonces actos sociales, mediados por el capital cultural y los recursos disponibles por sus protagonistas. A partir de las resistencias y los acomodos entre las partes en tensión, los imaginarios sobre la justicia y la efectividad de las normas que lo regulan en el tiempo y dentro de la sociedad, aquí hemos abordado algunas de las aristas y contradicciones de este tipo de atentados, cuya principal característica fue la focalización de la violencia en y hacia el cuerpo de las mujeres.

\section{Bibliografía}

\section{Fuentes Primarias y de Archivo}

Alfonso X El Sabio. Las Siete Partidas. Biblioteca Virtual Universal. Consultado en www.biblioteca.org.ar el 15 de marzo de 2016.

Archivo Nacional Santiago de Chile (ANS). Fondo Judiciales de Concepción (FJC). 1872. Judicial criminal contra José Cruz Soto por violación y estupro de una niña. Leg. 193. exp. 28, fjs.1-25.

ANS. FJC. 1849. Judicial Criminal en contra de Justo Yáñez por violación y estupro de una niña. Leg. 103, Pieza 7, Concepción.

ANS. FJC. 1864. Judicial Criminal contra Cipriano Gaete por la violación de Gertrudis Astudillo, Concepción 1864, Leg. 159, Pza. 4.

ANS. FJC. 1864. Judicial criminal contra Miguel Tiznado y otro por estupro y violación de Juliana Inojoza. 20 de marzo de 1864. Concepción. Leg. 194. exp. 8.

ANS. FJC. 1898. Judicial criminal contra Pedro Millaguir y Pablo Lepillán. Por violación y robo. 14 de enero de 1898. Concepción. Caja 65. Pza. 14.
Código Civil República de Chile. 1855. Imprenta de la República. Santiago.

Código Penal República de Chile. 1874. Imprenta de la República de Jacinto Núñez, Santiago

De Cobarrubias, Sebastián. 1611. Tesoro de la lengua castellana o Española. Madrid.

Diccionario de la Lengua Castellana o Diccionario de Autoridades. 1726-1739. Imprenta de Cámara de S.M. Madrid.

Real Recopilación de Leyes de los reinos de las indias. Mandadas imprimir y publicar por la Majestad Católica del Rey Don Carlos II, Nuestro señor. 1681. Impresa en Madrid por Ivlian de Paredes. Tomo IV. Año 1681.

Novísima Recopilación de las Leyes de España. Mandada formar por el Señor Don Carlos IV. 1805. Impresa en Madrid. Tomo V.

\section{Bibliografía General}

Agüero, A. 2008. Castigar y perdonar cuando conviene a la República. La justicia penal de Córdoba del Tucumán. Siglos XVII 
y XVIII. Madrid: Centro de estudios políticos y constitucionales.

Albornoz, M. 2007. "El mandato del silencio perpetuo. Existencia, escritura y olvido de conflictos cotidianos. Chile, 17201840". Justicia, poder y sociedad: recorridos históricos. Chile, Siglos XVIII-XIX. Cornejo, T. y González, c. (dirs.). Santiago: Ed. Universidad Diego Portales. 17-55.

.2009. "El precio de los cuerpos maltratados: discursos judiciales para comprar la memoria de las marcas de dolor. Chile, 1773-1813". Nuevo Mundo Mundos Nuevos. Disponible en http://nuevomundo.revues.org/55888; DOI: 10.4000/ nuevomundo.55888 (consultado el 25 de mayo de 2015).

. 2013. "Violencias cotidianas en femenino. Desbordes "naturales del sexo" ... ¿o rendijas, cegueras e impotencias del orden? Chile, 1800-1874". Escrita con sangre. Historia de la violencia en América Latina: siglos XIX y XX. Goicovic, I., Pinto, J. y Lozoya, I. (comps.). Santiago: Ceibo Ediciones. 76-79.

. 2014. "Casos de corte y privilegios de pobreza: los lenguajes jurídicos coloniales y republicanos para el rescate de derechos especiales en el momento de litigar por injurias. Chile, 1700-1874". Revista Signos Históricos 32: 48-85.

Araya, A. 2007. "La fundación de una memoria colonial: la construcción de sujetos y narrativas en el espacio judicial del siglo XVIII". Justicia, poder y sociedad: recorridos históricos. Chile, Siglos XVIII-XIX. Cornejo, T. y González, C. (dirs.). Santiago: Ed. Universidad Diego Portales. 185-218.

.2006. "El castigo físico: el cuerpo como representación de la persona, un capítulo de la historia de la occidentalización de América, Siglos XVI-XVIII". Revista Historia 39: 349-367.

2014. "Azotar. El cuerpo, prácticas de dominio colonial e imaginarios del Reino a la República de Chile". Formas de control y disciplinamiento. Chile, América y Europa, siglos XVI y XIX. Undurraga, V. y Gaumé, R. (eds.). Santiago: Uqbar Editores. 194-215.

Armand-Duc, N. 1993. "Las contradicciones del derecho". Historia de las mujeres. Duby, G., Perrot, M. (Eds). España: Ediciones Taurus Minor.

Brangier, V. 2011. "Justicia Criminal en Chile, 1842-1906 ¿Debido proceso o contención social?”. Sociedad y Equidad. Disponible en: <http://www.sye.uchile.cl/index.php/RSE/article/ view/10606/10845 (Consultado en 25 mayo.

2013. "Sentidos de lo justo e injusto. Judicialización de conflictos interpersonales, Chile Central, 1824-1875". Revista Historia y Justicia 1: 1-33.

2014. "Hacia la construcción de un esquema de administración de justicia en Chile en el siglo XIX. El papel ambivalente de los jueces letrados: entre las estructuras judiciales y el legalismo". Justicia y vida cotidiana en Valparaíso. Siglos XVIIIXIX. Correa, M. (coord.). Santiago: Acto Editores. 34-57.

Bravo, V. 2015. "Me urge se me suministre de sus bienes los alimentos": Estrategias femeninas en la resolución de conflictos domésticos. 1800-1850, Valle Central de Chile". Revista de Historia Social y de las Mentalidades 2 (19): 79-103.

Candau, M. 2004-2005. "Honras perdidas por conflictos de amor. El incumplimiento de las palabras de matrimonio en Sevilla moderna: un estudio cualitativo". Revista Fundación 7: 179-182. 2014. Las mujeres y el honor en la Europa Moderna. Huelva: Universidad de Huelva Publicaciones. 16.

Cobos, M. 1985. "Esquemas de la administración de justicia en las áreas rurales chilenas". Revista de Derecho Universidad Católica de Valparaíso 9: 65-88.

Collyer, J. 2010. Pecar como Dios manda. Historia sexual de los chilenos. Santiago: Editorial Catalonia.

Cornejo, T. 2007. "Testimonios y testigos: el problema de la fuente". Poder y sociedad en Chile: recorridos históricos. Cornejo, T. y González, C. (edit.). Santiago: Ediciones Universidad Diego Portales.

Cover, R. 2002. Derecho, narración y violencia. Poder constructivo y poder destructivo en la interpretación judicial. España: Ediciones Gedisa.

Escriche, J. 1874. Diccionario razonado de legislación y jurisprudencia. ( $3^{a}$ edición). Madrid: Librería de la Sra. Viuda e hijos de don Antonio Calleja.

Estrada, R. 2010. "El cuerpo abusado y el imaginario médico y legal en la comprobación del delito". Revista Nuevo mundo, mundos nuevos. Disponible en http://nuevomundo.revues. org/58837 (Consultadael 25 de mayo de 2015).

Farge, A. 2008. Efusión y tormento. El relato de los cuerpos. Historia del pueblo en el siglo XVIII. Buenos Aires: Katz Editores.

Fries, L. y Matus, V. 1999. "Sexualidad y reproducción, una legislación para el control: el caso chileno". Género y derecho. Alda, F. Y Fries, L. (eds.). Santiago: LOM. 139-143.

Foucault, M. 2005. La verdad y otras formas jurídicas. Madrid: Ediciones Gedisa.

Libros.

2014. Las redes del poder. Buenos Aires: Prometeo

Gil Ambona, A. 2008. Historia de la violencia contra las mujeres. Madrid: Ediciones Cátedra.

Goicovic, I. 2004. "Consideraciones teóricas sobre la violencia social en Chile (1850-1930)", Revista Última Década, №21, DIDPA, Valparaíso, diciembre 2004, 121-145.

2006. "Los escenarios de la violencia popular en la transición al capitalismo". Espacio Regional 3 (1): 75-80. 2006 "Relaciones afectivas y violencia intrafamiliar en Chile Tradicional”. Revista Iberofórum I (I): 1.21. Disponible en www.redalyc.org/articulo.oa?id21105574009 (consultado el 01 de agosto de 2015).

2013. "Introducción. Los modelos interpretativos en el estudio de la violencia". Escrita con sangre. Historia de la violencia en América Latina: siglos XIX y XX. Goicovic, I., Pinto, J. y Lozoya, I. (comps.). Santiago: Ceibo Ediciones. 11.

Goffman, E. 2006. Estigma. La identidad deteriorada. Buenos Aires: Amorrortu Editores.

González, Y. 2011. Conflicto y violencia sexual y formas de transgresión moral en el Obispado de Concepción. 1750-1890. Tesis Doctorado en Historia Iberoamericana. España: Universidad de Huelva. 
2012. "Las cifras del deshonor. Violencia sexual en el Obispado de Concepción, 1750-1890". Revista de Estudios Trasandinos 1 (17): 89-106.

Le Bretón, D. 1992. La sociología del cuerpo. Buenos Aires: Nueva Visión.

1995. Antropología del cuerpo y la modernidad. Buenos Aires: Nueva Visión.

1999. Las pasiones ordinarias. Antropología de las emociones. Buenos Aires: Nueva Visión.

León León, M. 2015. Construyendo un sujeto criminal. Criminología, criminalidad y sociedad en Chile. Siglos XIX y XX. Santiago: Editorial Universitaria.

León Solís, L. 2007. "Entre la alegría y la tragedia. Los intersticios del mundo mestizo en la frontera". Historia de la vida privada en Chile. El Chile Tradicional de la conquista a 1840. Sagredo, R. y Gazmuri, C. Santiago: Ediciones Taurus. 274-275.

Mantecón, T. 2014. "Disciplinamiento social, escenografías punitivas y cultura plebeya en el Antiguo Régimen". Formas de control y disciplinamiento. Chile, América y Europa, siglos XVI y XIX. Undurraga, V. y Gaumé, R. (eds.). Santiago: Uqbar Editores. 169-193.

Muchembled, R. 2010. Una historia de la violencia. Del final de la edad media a la actualidad. México: Ediciones Paidós.

Palma, D. 2014. "La formación de una justicia republicana. Los atribulados jueces del orden portaliano, 1830-1850". Justicia y vida cotidiana en Valparaíso. Siglos XVIII-XIX. Correa, M. (coord.). Santiago: Acto Editores Pp. 13-32.

Pérez, E. y Ortega, E. 2014. Cartografías del cuerpo. Biopolíticas de la ciencia y la tecnología. España: Serie Feminismos Ediciones Cátedra Universitat de Valencia. 31-32.

Ramos, C. 2008. "Cuerpos construidos, cuerpos legalizados. Ley y cuerpo en México de "fin de siècle". Enjaular los cuerpos. Normativas decimonónicas y feminidad en México. México: Ediciones COLMEX. 74.

Riva, B. 2014. "Cómplices y coautores del hecho. Delitos sexuales "en grupo" en la Provincia de Buenos Aires (1863-1903)". Revista Historia y Justicia 3: 285-316.

Rojas Gómez, M. 2008. Las voces de la justicia. Delito y sociedad en Concepción (1820-1875. Atentados sexuales, pendencias, bigamia, amancebamiento e injurias. Santiago: Colección Sociedad y Cultura, Centro de investigaciones Barros Arana.

Rojas Flores, J. 2015. "Los niños y su historia: un acercamiento conceptual y teórico desde la historiografía". Revista Pensamiento Crítico 1(23). Disponible en www.archivochile.com (consultado el 16 de agosto de 2015).

Salinas, R. 1995. "La pareja: comportamientos, afectos, sentimientos y pasiones". Historia de la vida privada en Chile. El chile moderno. 1840-1925. Sagredo, R. y Gazmuri, C. Santiago: Ediciones Taurus. 1-20

2010. "Cuerpo y erotismo en Chile". Fragmentos para una historia del cuerpo en Chile. Góngora, A. \& Sagredo, R. (eds.). Santiago: Ediciones Taurus.

Sedeillán, G. 2009. "Los delitos sexuales: la ley y la práctica judicial en la provincia de Buenos Aires durante el periodo de codificación del derecho penal argentino (1877-1892)". Revista Historia Crítica 37: 100-119.

Tausiet, M. y Amelang, J. 2009. Accidentes del alma: Las emociones en la edad moderna. Madrid: Editorial ABADA.

Tuñón, J. 2008. Enjaular los cuerpos. Normativas decimonónicas y feminidad en México. México: Ediciones COLMEX.

Undurraga, V. 2004. "El honor no es más que la buena opinión: Aproximación al honor a partir de la categoría de lo público en el Chile de 1792 a 1822". Revista de Historia de Chile y América 4: 17-35.

2008. "Cuando las afrentas se lavaban con sangre: Honor, masculinidad y duelos de espada en el siglo XVIII chileno". Historia 41(1):165-188.

. 2008. "Venganzas de sangre y discursos de honor en Santiago de Chile, siglo XVIII". Colonial Latin American Historical Review (CLAHR), Spanish Colonial Research Center, University of New México, Albuquerque, USA: 208-236.

2010. "Ritos de violencia. Reflexiones en torno a los hechos de sangre y las identidades de sus protagonistas en Santiago de Chile, siglo XVIII". La sociedad colonial en los confines del imperio. Diversidad e identidad (siglos XVI-XIX). Mayo, S. (Comp.). Córdoba: Universidad Nacional de La Plata. 60-87. 2010. "Valentones, alcaldes de barrio y paradigmas de la civilidad. Conflictos y acomodaciones en Santiago de Chile, siglo XVIII". Historia Social y de las mentalidades 14: 35-71. 2012. Los rostros del honor. Normas culturales y estrategias de promoción social en Chile Colonial. Santiago: Siglo XVIII, Editorial Universitaria, DIBAN, Centro de Investigaciones Diego Barros Arana. 21-32.

Undurraga V. y Gauné, R. 2014. "Diálogos y propuestas historiográficas desde un espacio de disciplinamiento", En Undurraga, Verónica y Gaumé, Rafael (eds.). Formas de control y disciplinamiento. Chile, América y Europa, siglos XVI y XIX, Uqbar Editores, Santiago, Santiago 2014, 21-45.

Vasallo, J. 2005. "Familias y control social en la Córdoba borbónica”. Revista Anuario. 8: 515-528.

Vigarello, G. 1999. Historia de la violación siglos XVI-XX Madrid: Ediciones Cátedra. 